\section{A plea for re-illusionment}

Burns' cri de coeur ${ }^{7}$ about the thoughtless severing of inpatients from community responsibility will strike a chord in colleagues of his demographic. Our generation saw the special contribution of the consultant psychiatrist as encompassing continuity of care across time and space in ways unique to our discipline. We hoped to see our patients holistically through the vicissitudes of illness, recovery, health and relapse, creating, when things went well enough, a deep life-enhancing mutual knowledge. Yes, we were spread thin, the workload was tough at times, and Jacks of all trades (psychotherapy, group and systemic therapy, psychopharmacology) must sometimes give way to master-craftsmen. But has psychiatry traded an easier life for a diminishing and less satisfying role? How long before an impoverished state finds our profession largely redundant? Are we in danger of becoming our own gravediggers? Or is all this merely nostalgia seasoned with generational grumpiness? Re-illusionment please!

1 Burns T. The dog that failed to bark. Psychiatrist 2010; 34: 361-3.

Jeremy Holmes Visiting Professor, Department of Clinical Psychology, University of Exeter, UK, email: j.a.holmes@btinternet.com

doi: $10.1192 /$ pb.34.11.497

\section{Because of the mental disorder . . .}

Short-term detention for mental disorder under the Mental Health (Care and Treatment) (Scotland) Act 2003 requires an approved medical practitioner to certify that a condition specified in Section 44(4)(b) of the Act is met: namely that 'because of the mental disorder, the patient's ability to make decisions about the provision of medical treatment is significantly impaired'.

Many practising clinicians will realise that there are myriad reasons why patients with mental disorder will not, for example, take necessary medication. These include family attitudes and previous adverse experiences, as well as factors caused by the mental disorder itself such as delusional beliefs. Clinical discussions surrounding a recent tribunal I attended have crystallised this for me.

Was it really the view of the Scottish Parliament that a patient who refuses medication for a severe psychotic exacerbation on grounds not actually caused by this illness should remain untreated?

Stephen J. Carey Consultant in Adult Psychiatry, NHS Fife, Scotland, UK, email: stephen.carey@nhs.net

doi: 10.1192/pb.34.11.497a

\section{How many is too many?}

I write in response to the letter from Neelam \& Williams. ${ }^{1}$ The authors are responding to the paper by Singhal et $a l_{,}{ }^{2}$ who elicited the views of service users and providers with regard to separate consultant teams for in-patients and out-patients. Neelam \& Williams described the use of a third team - the crisis resolution home treatment team (CRHTT), saying that this team performs a vital role in the period between discharge from the in-patient team and the patient being sufficiently well for safe and effective transfer into the community mental health team (CMHT).
The most consistent theme that emerged from Singhal et al's study was the difficulties in continuity of care and maintaining the therapeutic relationship when patients moved from the in-patient to the CMHT. It seems rather bizarre that Neelam \& Williams contend that the problem can be ameliorated by introducing yet a third team into the discontinuity between in-patient and out-patient care. Neelam $\&$ Williams note that patients often asked to remain permanently under the care of the CRHTT and it seems probable that these patients are seeking a return to the more traditional model of continuity of care from one single team.

I write as a trainee psychiatrist who has worked only in generic psychiatric teams that care for patients whether they are in-patients or living in the community. In my experience, these teams provide high-quality care and encounter no difficulties in continuity and maintaining therapeutic relationships. Perhaps an advocate of New Ways of Working ${ }^{3}$ could explain to me the advantages of an ever-increasing 'specialist team' approach as opposed to the 'one patient, one team' model?

1 Neelam K, Williams F. Three consultants for one patient. Psychiatrist 2010; 34: 357.

2 Singhal A, Garg D, Rana AK, Naheed M. Two consultants for one patient: service users' and service providers' views on 'New Ways'. Psychiatrist 2010; 34: 181-6.

3 Department of Health. Mental Health: New Ways of Working for Everyone. Department of Health, 2007.

Gemma Fleming CT2 Psychiatry Trainee, Aberdeen, Scotland UK, email: gemmafleming@nhs.net, John Eagles Professor, Consultant Psychiatrist (General Adult Psychiatry), Cornhill Hospital, Aberdeen.

doi: 10.1192/pb.34.11.497b

\section{Psychiatrists behaving badly?}

The reason why many of us choose psychiatry as our specialty is that we like the human touch of medicine. To a large extent this is our strongest attribute, but as O'Leary et al have demonstrated, quite perversely it is this affinity that also leads to our failing in the areas we should excel in, namely relationships with colleagues and patients as well as good clinical practice. The implications of the numbers of psychiatrists being referred to the National Clinical Assessment Service (NCAS) should not be underestimated not least to themselves but also to mental services as a whole. Coupled with the recruitment problems in junior training posts and the relative inability to make our specialty attractive to medical undergraduates, ${ }^{2}$ we are likely to store further problems of recruitment to consultant posts, something that has dogged our profession for many decades but none more so than in the 1980s and 1990s. Elsewhere in the journal, Burns articulates his concerns on how the consultant's role lacks definition, ${ }^{3}$ a factor that might well influence our performance and our attitude to others, as well as others' to us. My sense is that we need some creative thinking around how we might promote our specialty, while simultaneously ensuring that our colleagues are supported in the right manner during their stressful years of practice. In this regard, O'Leary et al's call for the College to review the continuing professional development (CPD) programme is not inappropriate, but as the CPD Committee has just set out a new policy ${ }^{4}$ it could be some time before the next policy comes round. There is evidence 
that those who participate in CPD are less likely to be disciplined than those who do not and that those who are in mature professional years fare better if they keep up to date with modern practice. ${ }^{5}$ There is scope within the three domains (clinical, professional and academic) of the new CPD policy to cover all specialty developmental issues while retaining generic medical and psychiatric skills. These might be further reinforced through peer groups. Each of the College faculties has had the opportunity to influence the policy, but I am in agreement with O'Leary et al that further refinement could take place to reflect the growing need to provide specialist care. It would be my aspiration that the CPD policy be more electronically based rather than being set in a publication which sits on the shelf for the next 5 years or more without being updated. I would welcome members' input into how this might be achieved annually, with revision of policy that is in line with their practice.

\section{Declaration of interest}

J.S.B. chairs the Royal College of Psychiatrists' CPD Committee.

1 O'Leary D, McAvoy P, Wilson J. Performance concerns in psychiatrists referred to the National Clinical Assessment Service. Psychiatrist 2010; 34: 371-5

2 Burns T. The dog that failed to bark. Psychiatrist 2010; 34: 361-3.

3 BMA Board of Medical Education. Selection for Specialty Training. BMA, 2006 (http://www.bma.org.uk/images/ SelectionSpecialtyTraining_tcm41-147106.pdf ).

4 Royal College of Psychiatrists. Good Psychiatric Practice: Continuing Professional Development (2nd edn). College Report CR157. Royal College of Psychiatrists, 2010.

5 Bamrah JS, Bhugra D. CPD and recertification: improving patient outcomes through focused learning. Adv Psychiatr Treat 2009; 15: 2-6.

J. S. Bamrah Director of CPD, Royal College of Psychiatrists, London, email: jsbamrah@aol.com

doi: 10.1192/pb.34.11.497c

\section{Routine outcome measures in liaison psychiatry}

Jacobs \& Moran, ${ }^{1}$ in their article enthusiastically supportive of the use of Health of the Nation Outcome Scales (HoNOS) as a routine outcome measure, recommend 'mild coercion' by trust managers to improve completion rates. They acknowledge the bluntness of the instrument and its inappropriateness in some specialist services but fail to consider that it may be totally inapplicable in some psychiatric specialties, one of which is liaison psychiatry.

The authors state the truism that for HoNOS to be considered an outcome measure, there need to be paired ratings. Liaison psychiatry services see patients mainly in emergency departments (A\&E) and in-patient medical units. The A\&E assessments are mainly one-off assessments where paired assessments are inapplicable. The average stay for acute care in the UK is about 6 days; $^{2}$ thus there are few patients on medical wards where paired ratings with a space of at least 2 weeks between them are possible.

Another problem in using HoNOS as an outcome measure, even in the few cases where it may be possible, is the nature of consultation-liaison work. The consultations are often directed at the referring medical team, examples including clarifying a complex capacity situation or advising on change in psychopharmacology in patients with organ impairment. Even when the consultation is patient-focused the interventions are not necessarily aimed at bringing about symptomatic change in a short period of time. Thus, HoNOS would at best fail to capture relevant outcomes and at worst seriously misrepresent the effectiveness of liaison psychiatry teams.

This is not to say that outcome measures are not important in liaison psychiatry but they need to be smarter. Operational definitions for consultation outcomes that focus on the effectiveness of individual consultations should be agreed - such an approach has been recently studied by a Brazilian group. ${ }^{3}$ Quality of liaison psychiatry services should be judged by looking at consultation outcomes and performance standards such as those recently published by the Psychiatric Liaison Accreditation Network. ${ }^{4}$

1 Jacobs R, Moran V. Uptake of mandatory outcome measures in mental health services. Psychiatrist 2010; 34: 338-43.

2 Organisation for Economic Co-operation and Development. Health at a Glance: OECD Indicators. OECD, 2007.

3 de Albuquerque Citero $\mathrm{V}$, de Araujo Andreoli PB, Nogueira-Martins LA Andreoli SB. New potential clinical indictors of consultation-liaison psychiatry's effectiveness in Brazilian general hospitals. Psychosomatics 2008; 49: 29-38.

4 Palmer L, Dupin M, Hinchcliffe G, McGeorge M (eds). Quality Standards for Liaison Psychiatry Services. Royal College of Psychiatrists, 2009 (http://www.rcpsych.ac.uk/pdf/

PLAN\%20Standards\%20First\%20Edition\%20Sep2009.pdf).

Gopinath Ranjith Consultant Liaison Psychiatrist, Department of Liaison Psychiatry, St Thomas' Hospital, London, UK, email: Gopinath.Ranjith@kcl.ac.uk

doi: $10.1192 /$ pb.34.11.498

\section{Women in academic psychiatry: view from India}

Dutta et al discuss various reasons for underrepresentation of women psychiatrists in senior positions across academic medicine from high-income countries. We would like to share our experience from India as a representative of low-income countries.

Over the past few decades, the number of women psychiatrists in India has been on the rise and they constitute about $15 \%$ of the total number of psychiatrists. However, most of them work in junior positions, with only about $10 \%$ in senior positions. $^{2}$ The women psychiatrists in India are represented in different health sectors such as general hospital psychiatric units, psychiatric hospitals and the office-based practice. The majority of the premier medical schools of the country have women faculty but mostly in junior positions. Some also head academic departments in different parts of the country, and a few have headed a medical school in the past. Some of the women psychiatrists in the country have also taken leadership roles in areas of child psychiatry, suicide prevention, community psychiatry, rehabilitation of patients with schizophrenia and issues related to women's mental health. A few have held the position of the President of the Indian Psychiatric Society, the national body of psychiatrists. Although the Indian Journal of Psychiatry, the official journal of the Society, has never had a woman editor, some of the journals published by the constituent zones of the national Society did have women editors. One of them, the Journal of Mental Health and Human Behaviour, is edited by a woman psychiatrist. Critically seen as a whole, the original articles and some case reports make the 